\title{
The Crystal Chemistry and Electrical properties of Fe doped $\mathrm{Ca}_{12} \mathrm{Al}_{14} \mathrm{O}_{33}$ (Mayenite)
}

\author{
S. N. Ude ${ }^{1 *}$ C. J. Rawn², T. T. Meek ${ }^{3}$ \\ ${ }^{1,2,3}$ Department of Materials Science and Engineering, University of Tennessee Knoxville, Knoxville TN. 37996, U.S.A. \\ ${ }^{2}$ Materials Science and Technology Division, Oak Ridge National Laboratory, Oak Ridge, TN. 37831, U.S.A.
}

\begin{abstract}
$X$-ray and neutron powder diffraction have been used to study the crystal chemistry of Fe doped mayenite $\left(\mathrm{Ca}_{12} \mathrm{Al}_{14-x} \mathrm{Fe}_{x} \mathrm{O}_{33}\right)$. Solidstate synthesis was used to prepare $\mathrm{Ca}_{12} \mathrm{Al}_{14-x} \mathrm{Fe}_{x} \mathrm{O}_{33}$ where $x=0,0.1,0.2,0.5$ and 0.6 and the citrate gel route was used to prepare $\mathrm{Ca}_{12} \mathrm{Al}_{14-x} \mathrm{Fe}_{x} \mathrm{O}_{33}$ where $\mathrm{x}=0,0.05,0.1,0.2,0.3$ and 0.4. X-ray powder diffraction data indicate that samples with the same composition but synthesized by the citrate gel route were more likely to be phase pure than samples obtained by traditional solidstate synthesis. The refined lattice parameters were observed to increase with increasing Fe concentration, irrespective of the synthesis method. Refined neutron powder data confirm that Fe is going into Al site rather than Ca site. A 2-point probe was used to measure the electrical properties of the Fe doped citrate gel synthesized samples and showed that the resistivity increases for the Fe doped samples compared to the undoped mayenite.
\end{abstract}

Keywords: Mayenite, Neutron Diffraction, X-ray Diffraction, Sol-Gel

\subsection{INTRODUCTION}

The mineral mayenite, $\mathrm{Ca}_{12} \mathrm{Al}_{14} \mathrm{O}_{33}$, has been traditionally known as a constituent of Portland cements. It crystallizes with a body centered cubic crystal structure belonging to the $I-43 d$ (number 220) space group with $a$ $=11.989 \AA$ with 2 formula units per unit cell [1]. In recent decades mayenite's interesting electrical, optical, and catalytic properties have been discovered [2-11]. These interesting physical properties result from its unique framework structure that allows various anions to be distributed among the cages formed by the framework [6, $12,13]$.

Since many attractive physical properties are a result of point defects, it is of interest if cation substitutions can be made in the framework of mayenite and how these defects would affect the anion distribution inside the cages and ultimately the conductivity of mayenite. Will the conductivity change by introducing point defects replacing either $\mathrm{Ca}^{2+}$ or $\mathrm{Al}^{3+}$ by $\mathrm{Fe}^{2+}$ or $\mathrm{Fe}^{3+}$ and if so how much of the $\mathrm{Ca}$ and/or $\mathrm{Al}$ can be replaced by $\mathrm{Fe}$ ? A ternary phase diagram of the $\mathrm{CaO}-\mathrm{Al}_{2} \mathrm{O}_{3}-\mathrm{Fe}_{2} \mathrm{O}_{3}$ system, shown in Figure 1, indicates there is a limited range of Fe incorporation into the mayenite structure [14]. Boysen et al. [15] used neutron powder diffraction to characterize samples with 0.1 and $2.5 \mathrm{~mol} \% \mathrm{Fe}$ synthesized by the sol-gel method, and indicated that doping mayenite with Fe suppressed the incorporation of

* Corresponding author (Tel: +234 (0) 809892 5854)

Email addresses: sabina.ude@unn.edu.ng (S.N. Ude), crawn@utk.edu (C. J. Rawn), tmeek7@utk.edu (T. T. Meek) extra anions while exhibiting large disorder in the crystal structure and predicted high anionic conductivity due to the large observed disorder at room temperature and extreme delocalization at high temperatures. To date the effect of Fe on the electrical properties of mayenite has not been reported.

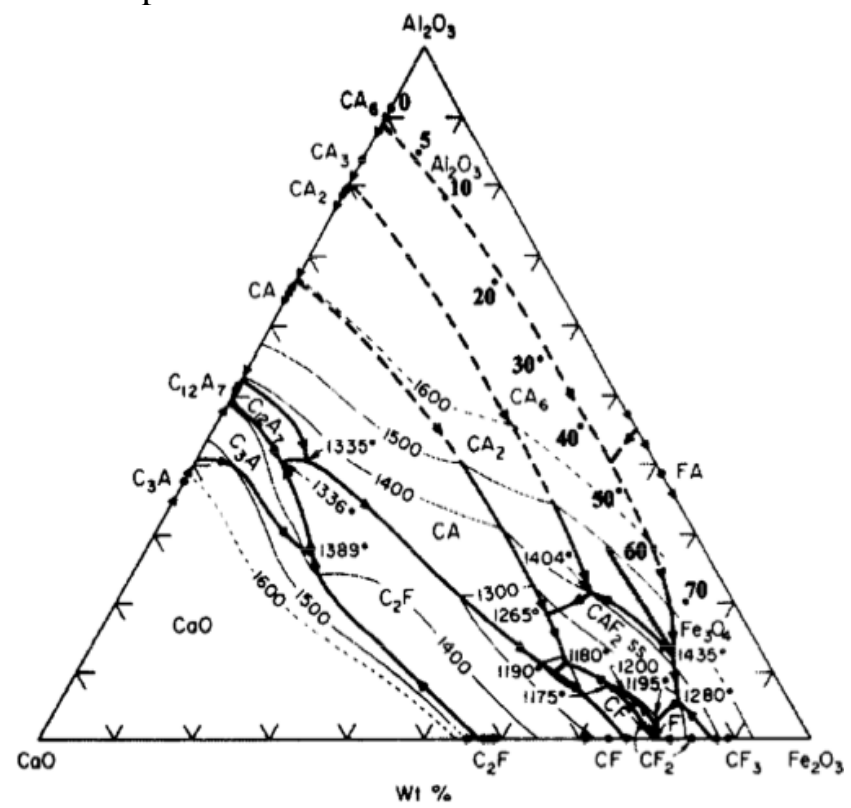

Figure 1: $\mathrm{CaO}-\mathrm{Al}_{2} \mathrm{O}_{3}-\mathrm{Fe}_{2} \mathrm{O}_{3}$ ternary phase diagram [1].

In this present work, pure and $\mathrm{Fe}$ substituted mayenite have been synthesized using both solid state and citrate gel techniques, and the resulting crystal structures characterized using X-ray and neutron powder diffraction. The electrical properties have been measured using a 2point probe. 


\subsection{MATERIALS AND METHODS \\ 2.1. Synthesis}

$\mathrm{Fe}$ doped $\left(\mathrm{Ca}_{12} \mathrm{Al}_{14-\mathrm{x}} \mathrm{Fe}_{\mathrm{x}} \mathrm{O}_{33}\right)$ mayenite was produced by both solid-state and citrate gel syntheses. Starting powders of $\mathrm{CaCO}_{3}$ (Fisher Chemicals, 99\%), $\mathrm{Al}_{2} \mathrm{O}_{3}$, (Alfa Aesar, 99.5\%) and $\mathrm{Fe}_{2} \mathrm{O}_{3}$ (Alfa Aesar, 99.95\%) were used as precursors for the solid-state synthesis where $\mathrm{x}=0,0.1,0.2,0.5$ and 0.6 . The samples were initially fired at $1200{ }^{\circ} \mathrm{C}$ for 16 hours. The final firing of the undoped mayenite was at $1350{ }^{\circ} \mathrm{C}$ for 23.5 hours, while the Fe doped samples were fired at $1350{ }^{\circ} \mathrm{C}$ for 18 hours. To explore if the final firing temperature of Fe doped samples could be lowered, samples where $\mathrm{x}=$ 0.2 and 0.6 were fired at 1200 and $1300{ }^{\circ} \mathrm{C}$ for $18 \mathrm{~h}$.

$\mathrm{Ca}\left(\mathrm{NO}_{3}\right)_{2} \bullet 4 \mathrm{H}_{2} \mathrm{O}$ (Fisher Chemical, 99.5\%), $\mathrm{Al}\left(\mathrm{NO}_{3}\right)_{3} \bullet 9 \mathrm{H}_{2} \mathrm{O}$ (Fisher Chemical, 98.9\%), $\mathrm{Fe}\left(\mathrm{NO}_{3}\right)_{3} \bullet 9 \mathrm{H}_{2} \mathrm{O}$ (Acros, 98\%) and citric acid $\left(\mathrm{C}_{6} \mathrm{H}_{8} \mathrm{O}_{7}\right)$ (Alfa Aesar, 99\%) were used as precursors for the citrate gel synthesis where $\mathrm{x}=0,0.05,0.1,0.2,0.3$ and 0.4 . The resulting powder was divided in half and one half was used to press pellets and subsequently fired at $1000^{\circ} \mathrm{C}$ for $4 \mathrm{~h}$ in air while the other half was pre-calcined at $600{ }^{\circ} \mathrm{C}$ as a loose powder and then pressed into pellets and fired in flowing $4 \% \mathrm{H}_{2} / 96 \% \mathrm{Ar}$ at $1200{ }^{\circ} \mathrm{C}$ for $6 \mathrm{~h}$. Details of both syntheses techniques can be found in Ude et al. [15].

\subsection{Characterization}

Samples characterized using X-ray and neutron diffraction were ground into fine powders. For the X-ray powder diffraction measurements, powders were back loaded into deep welled sample holders and spun during the data collection to improve sampling statistics. Data were collected on a PANalytical X'Pert PRO MPD $\theta-\theta$ diffractometer equipped with an X'celerator Real Time Multiple Strip (RTMS) detector allowing fast data collection.

The instrument was operated at $45 \mathrm{KV}$ and $40 \mathrm{~mA}$ and data were collected using $\mathrm{Cu} \mathrm{K} \alpha$ radiation over a $2 \theta$ range of $5-140^{\circ}$ with a count time set so that each data collection lasted approximately 20 minutes. X-ray powder diffraction data were analyzed using Jade [Jade 6.0, Materials Data Inc.] and HighScore [X'Pert HighScore Plus 3.0, PANalytical, Inc.] software packages for phase identification; and Rietveld refinements were performed using the EXPGUI graphical interface [16] for the General Structure Analysis System (GSAS) [17].

Neutron powder diffraction data were collected on samples synthesized using the citrate gel method where $\mathrm{x}=0$ and 0.3 . The diffraction measurements were carried out using the high resolution powder diffractometer (POWGEN) at the Spallation Neutron Source at Oak Ridge National Laboratory [18]. Samples were loaded in $6 \mathrm{~mm}$ diameter $\mathrm{V}$ cans and data were collected at room-temperature, using wavelength bands centered at 1.066 and $1.599 \AA$ covering a $d$ spacing range of $0.3-4.3 \AA$. Rietveld refinements on the collected data were performed using the GSAS software package [18] and the EXPGUI interface [17].

Electrical resistance measurements were collected on the citrate gel samples that were pressed into pellets and fired in reducing atmosphere where $\mathrm{x}=$ $0,0.05,0.1$, and 0.3 . The measurements were carried out using a 2-point probe between 0 to $20 \mathrm{~V}$ at a step size of $0.5 \mathrm{~V}$ and 0.1 compliance.

\subsection{RESULTS AND DISCUSSION \\ 3.1. Physical properties}

General physical observations of the pellets after firing included color changes. For both synthesis techniques the sample without Fe was white after firing in air compared to the samples containing $\mathrm{Fe}$ which were light green and became darker with increasing Fe content. Samples synthesized using solid-state method where $\mathrm{x}=$ 0.1 and 0.6 are shown in Figure 2a. Samples prepared using citrate gel method and fired in flowing $4 \% \mathrm{H}_{2} / 96 \%$ Ar turned black, as shown for $\mathrm{x}=0.1$ and 0.4 in Figure $2 \mathrm{~b}$. As the Fe content increased the samples were easier to grind. It has been noted that $\mathrm{Fe}$ increases the porosity thereby reducing their strength [19].

(a)

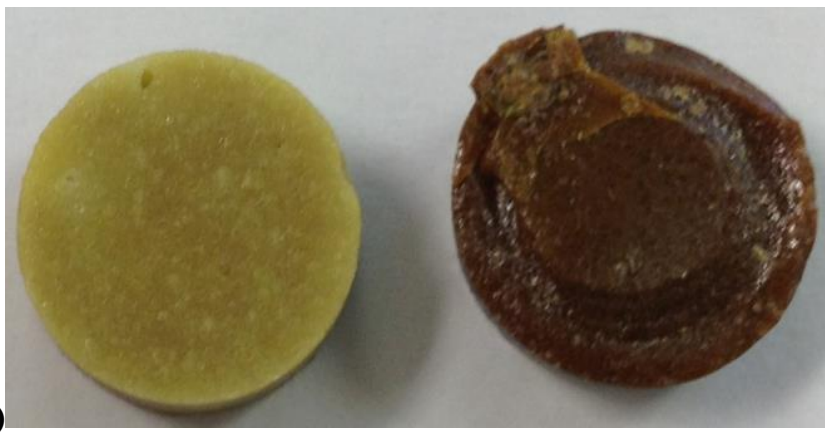

(b)

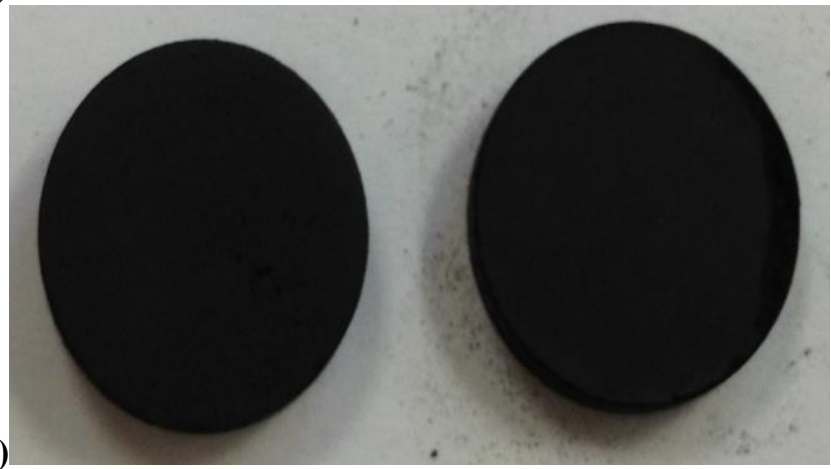

Figure 2: $\mathrm{Ca}_{12} \mathrm{Al}_{14-\mathrm{x}} \mathrm{Fe}_{\mathrm{x}} \mathrm{O}_{33}$ (a) where $\mathrm{x}=0.1$ (left) and 0.6 (right) synthesized using solid state techniques and fired in air and (b) where $\mathrm{x}=0.1$ (left) and 0.4 (right) synthesized using citrate gel techniques and fired in $4 \% \mathrm{H}_{2} / 96 \% \mathrm{Ar}$.

\section{2. $\quad X$-ray diffraction}

Figure 3 compares the $\mathrm{X}$-ray powder diffraction data for the $\mathrm{Ca}_{12} \mathrm{Al}_{14-\mathrm{x}} \mathrm{Fe}_{\mathrm{x}} \mathrm{O}_{33}$ samples prepared using the citrate gel route and fired at $1000^{\circ} \mathrm{C}$. Samples with $\mathrm{x}=0$, $0.05,0.1$, and 0.3 were single phase while the samples where $\mathrm{x}=0.2$ and 0.4 contained a minor amount (less than $0.1 \mathrm{wt} \%)$ 
of the meta-stable phase $\mathrm{Ca}_{5} \mathrm{Al}_{6} \mathrm{O}_{14}$. The double peaks belonging to $\mathrm{Ca}_{5} \mathrm{Al}_{6} \mathrm{O}_{14}$ are seen at $2 \theta=30.58^{\circ}$ and $31.02^{\circ}$.

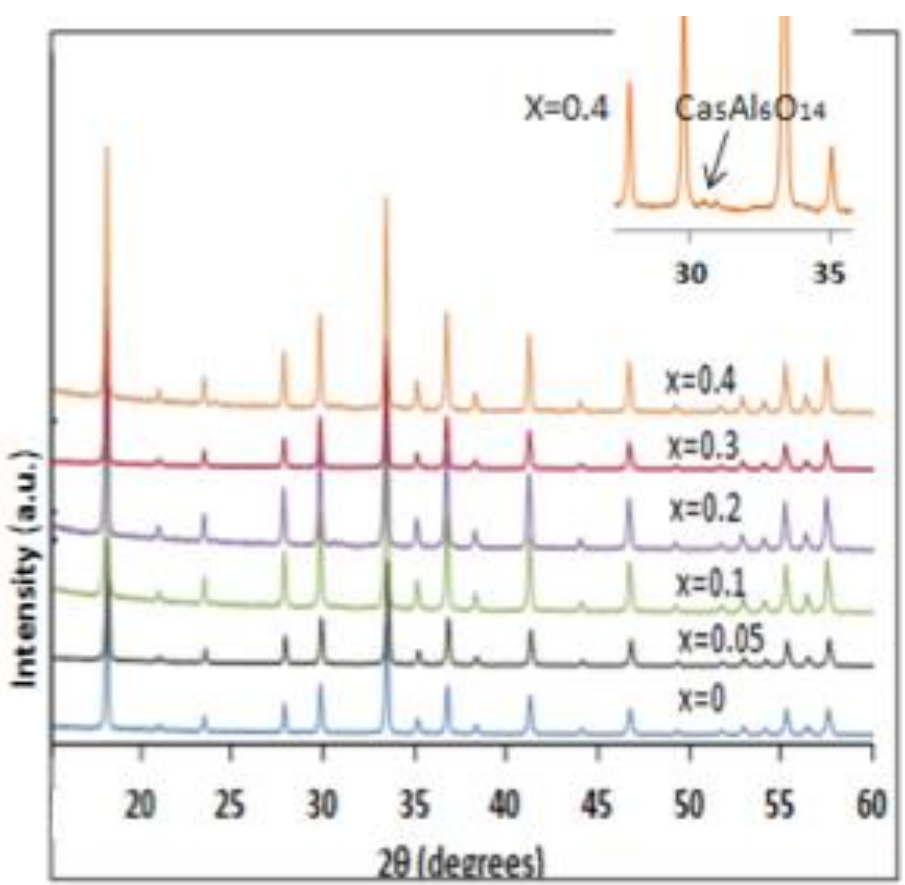

Figure 3: Powder X-ray diffraction data of $\mathrm{Ca}_{12} \mathrm{Al}_{14-\mathrm{x}} \mathrm{Fe}_{\mathrm{x}} \mathrm{O}_{33}$ synthesized using the citrate gel method and fired at $1000^{\circ} \mathrm{C}$.

Figure 4 compares $\mathrm{X}$-ray powder diffraction data for the $\mathrm{Ca}_{12} \mathrm{Al}_{14-\mathrm{x}} \mathrm{Fe}_{\mathrm{x}} \mathrm{O}_{33}$ samples prepared using solidstate synthesis and fired at $1350{ }^{\circ} \mathrm{C}$. Only the sample without $\mathrm{Fe}$ was single phase, all samples with $\mathrm{Fe}$ contained $\mathrm{Ca}_{3} \mathrm{Al}_{2} \mathrm{O}_{6}\left(\right.$ major peak position $2 \theta=33.21^{\circ}$ ) as a secondary phase and the refined weight fractions are given in table 1 . The samples where $\mathrm{x}=0.5$ and 0.6 had small amounts of $\mathrm{Ca}_{2} \mathrm{Fe}_{0.7} \mathrm{Al}_{1.3} \mathrm{O}_{5}$ (two major peaks located at $2 \theta=45.5^{\circ}$ and $34.1^{\circ}$ [21]) as an extra phase in addition to $\mathrm{Ca}_{3} \mathrm{Al}_{2} \mathrm{O}_{6}$. The presence of $\mathrm{Ca}_{2} \mathrm{Fe}_{0.7} \mathrm{Al}_{1.3} \mathrm{O}_{5}$ in both samples, suggests that incorporation of $\mathrm{Fe}$ beyond $\mathrm{x}$ $=0.4$ cannot yield single-phase solid solution of mayenite. $\mathrm{X}$-ray powder diffraction data on samples with $\mathrm{x}=0.2$ and 0.6 fired at 1200,1300 and $1350{ }^{\circ} \mathrm{C}$ did not change, suggesting that equilibrium can be reached at $1200{ }^{\circ} \mathrm{C}$ when mayenite is doped with $\mathrm{Fe}$ as compared to $1350{ }^{\circ} \mathrm{C}$ when undoped.

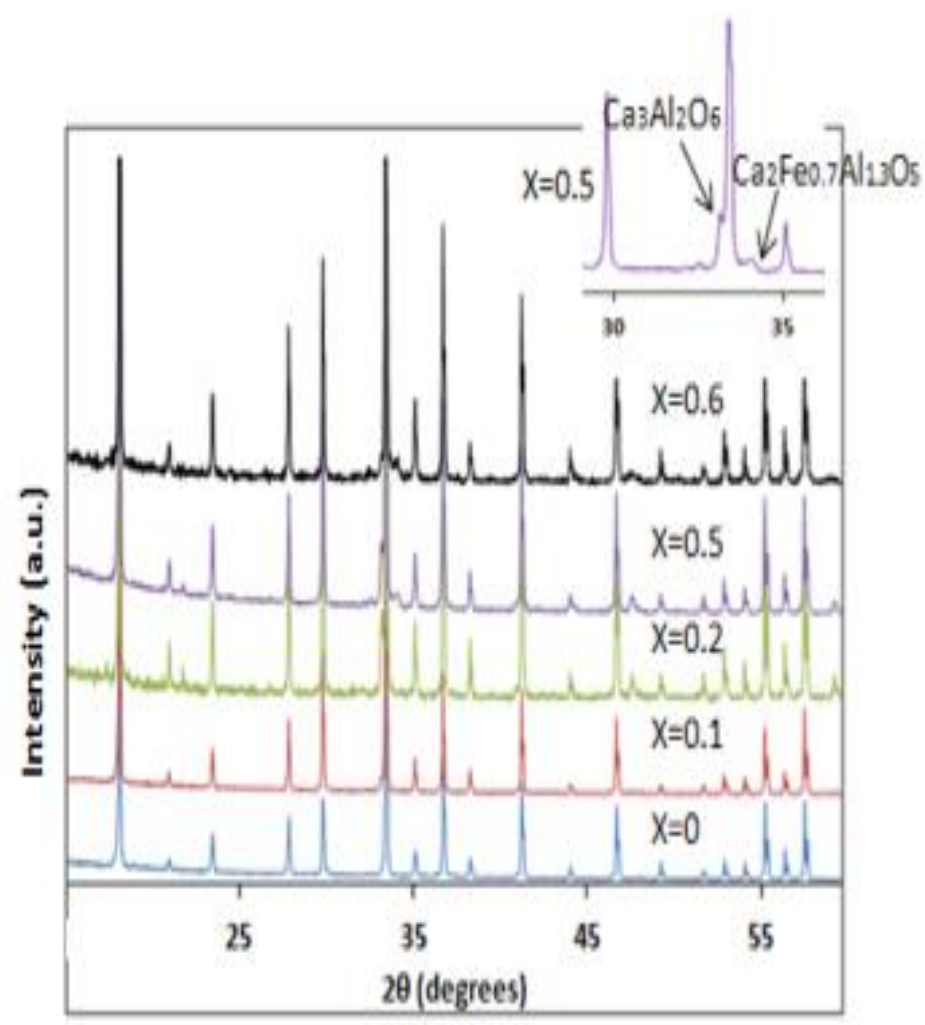

Figure 4: $\mathrm{X}$-ray powder diffraction data of $\mathrm{Ca}_{12} \mathrm{Al}_{14-\mathrm{x}} \mathrm{Fe}_{\mathrm{x}} \mathrm{O}_{33}$ synthesized using solid-state techniques.

Table 1: Phases identified using X-ray powder diffraction and refined wt $\%$.

\begin{tabular}{lll}
\hline Synthesis Technique & Fe (x) & Phases Present (wt \%) \\
\hline Solid-State & 0 & $\mathrm{C}_{12} \mathrm{~A}_{7}$ \\
0.1 & $\mathrm{C}_{12} \mathrm{~A}_{7}(99.7), \mathrm{C}_{3} \mathrm{~A}(0.3)$ \\
0.2 & $\mathrm{C}_{12} \mathrm{~A}_{7}(96.4), \mathrm{C}_{3} \mathrm{~A}(3.6)$ \\
0.5 & $\mathrm{C}_{12} \mathrm{~A}_{7}(95.9), \mathrm{C}_{3} \mathrm{~A}(3.4), \mathrm{C}_{2} \mathrm{AF}(0.7)$ \\
& 0.6 & $\mathrm{C}_{12} \mathrm{~A}_{7}(96.6), \mathrm{C}_{3} \mathrm{~A}\left(\right.$ less than 0.1), $\mathrm{C}_{2} \mathrm{AF}(3.4)$ \\
Citrate Gel & 0 & $\mathrm{C}_{12} \mathrm{~A}_{7}$ \\
& 0.05 & $\mathrm{C}_{12} \mathrm{~A}_{7}$ \\
& 0.1 & $\mathrm{C}_{12} \mathrm{~A}_{7}$ \\
& 0.2 & $\mathrm{C}_{12} \mathrm{~A}_{7}$ \\
& 0.3 & $\mathrm{C}_{12} \mathrm{~A}_{7}$ \\
& 0.4 & $\mathrm{C}_{12} \mathrm{~A}_{7}, \mathrm{C}_{5} \mathrm{~A}_{3}$ (less than 0.1) \\
\hline
\end{tabular}




\subsection{Neutron Powder Diffraction}

Figure 5 compares the lattice parameters, obtained from Rietveld refinements on the X-ray powder diffraction data collected on samples synthesized by both techniques. The mayenite structure reported by Bartl et al [20] was used as the starting structural model. For both synthesis techniques the lattice parameter showed an increase with increasing $\mathrm{Fe}$ concentration. For coordination number of 4 the ionic radius for $\mathrm{Al}^{3+}$ is 0.39 $\AA$, for $\mathrm{Ca}^{2+}$ the ionic radius is $1.00 \AA$ or greater depending on the coordination number, and for Fe the ionic radius can be anywhere between 0.49 and 0.77 depending on the valence (di- or tri-valent), coordination number and spin [Shannon and Prewit]. Based on the ionic radii the Fe will most likely replace the $\mathrm{Al}$ and expand the unit cell. The defect reaction of $\mathrm{Fe}^{3+}$ and replacing $\mathrm{Al}^{3+}$ in mayenite represented by Kroger-Vink notation is shown in equation 4-1 below.

$$
7 \mathrm{Fe}_{2} \mathrm{O}_{3} \stackrel{\mathrm{Ca}_{12} \mathrm{Al}_{14} \mathrm{O}_{33}}{\longrightarrow} 12 \mathrm{Ca}_{\mathrm{Ca}}^{x}+14 \mathrm{Fe}_{\mathrm{Al}}^{x}+33 \mathrm{O}_{\mathrm{O}}^{x}
$$
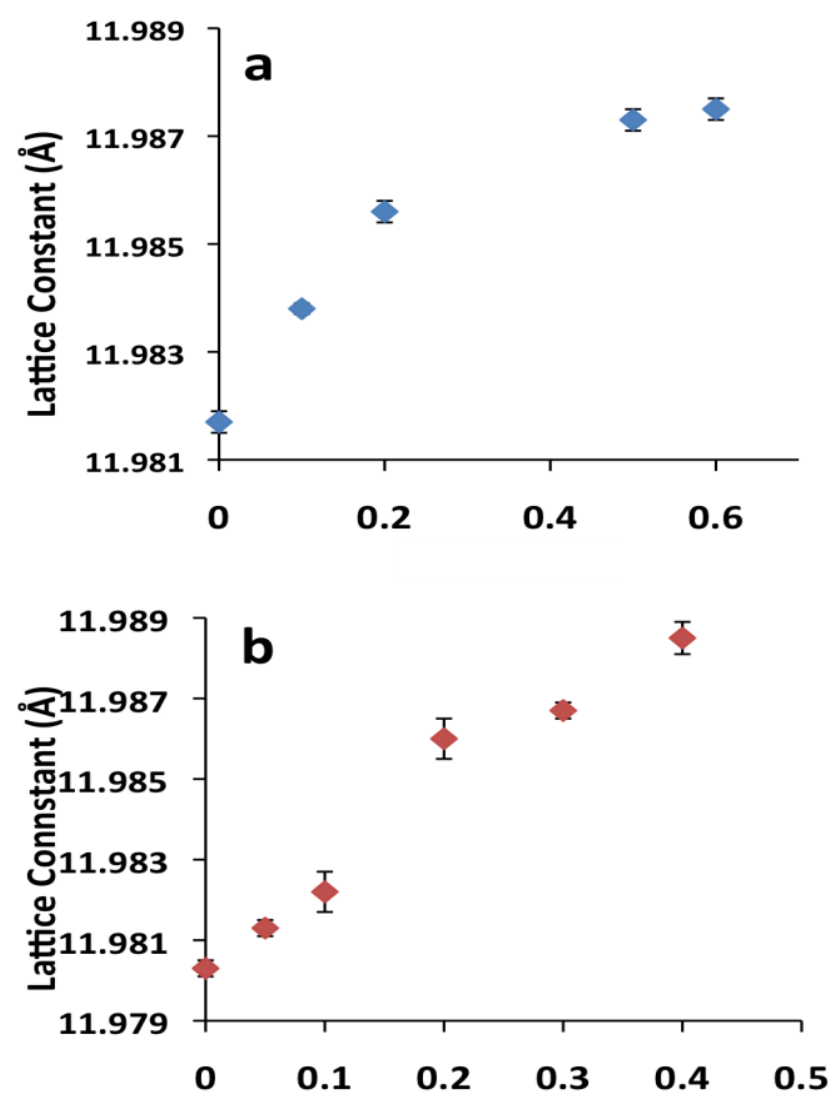

Figure 5: Plot of lattice constant versus Fe content for (a) solid state and (b) sol-gel synthesized samples.

The presence of the secondary phase $\mathrm{Ca}_{3} \mathrm{Al}_{2} \mathrm{O}_{6}$ in some of the samples as $\mathrm{Fe}$ content increases supports that the quantity of $\mathrm{Al}$ decreases while $\mathrm{Ca}$ increases as the reaction moves towards $\mathrm{CaO}$ rich region in the $\mathrm{CaO}-$ $\mathrm{Al}_{2} \mathrm{O}_{3}$ binary phase diagram. Results of the structural details refined from the neutron powder diffraction data, discussed below, provide additional evidence that $\mathrm{Fe}$ replaces the $\mathrm{Al}$ and does not go into $\mathrm{Ca}$ site.

Figure 6 shows the neutron powder diffraction data ( $\mathrm{I}_{\mathrm{obs}}$ ) collected at $298 \mathrm{~K}$ for the citrate gel base mayenite $(x=0)$, along with the calculated neutron powder diffraction pattern $\left(\mathrm{I}_{\text {calc }}\right)$, and the difference pattern $\left(\mathrm{I}_{\mathrm{obs}}-\mathrm{I}_{\mathrm{calc}}\right)$. The structure proposed by Bartl and Scheller [22], with only one Ca site (24d) and the O atom located on the $24 d$ site only partially occupied, was used as the starting model for the calculated pattern. Using this structural model full refinement on both the atomic positions and atomic displacement parameters was not possible. Using the structure proposed by Boysen et al. [21], with two partially occupied $\mathrm{Ca}$ atoms on different 24d sites and the $\mathrm{O}$ atom, that Bartl and Scheller [23] suggested was on the $24 d$ site, moved slightly to occupy a $12 a$ site, was used to model the calculated pattern and refinements using the two partially occupied Ca positions resulted in one of the $\mathrm{Ca}$ atom's atomic displacement parameters going non-positive definite. Moving the $\mathrm{O}$ from the $24 d$ site to the $12 a$ site and having only one $\mathrm{Ca}$ position resulted in improved fit. A total of 36 variables were refined including all atomic positions, atomic displacement parameters, the site occupancy for the $\mathrm{O}$ on the $12 a$ site and resulted in a $\chi^{2}=1.704$ ( R $w p=4.8 \%$ and Rexp $=3.71 \%$ ). Refining on the site occupancy factor (sof) of the $\mathrm{O}$ atom in the $12 a$ site revealed the site was about $1 / 4$ occupied resulting in a chemistry of $\mathrm{Ca}_{24} \mathrm{Al}_{28} \mathrm{O}_{67}$, slightly oxygen rich.

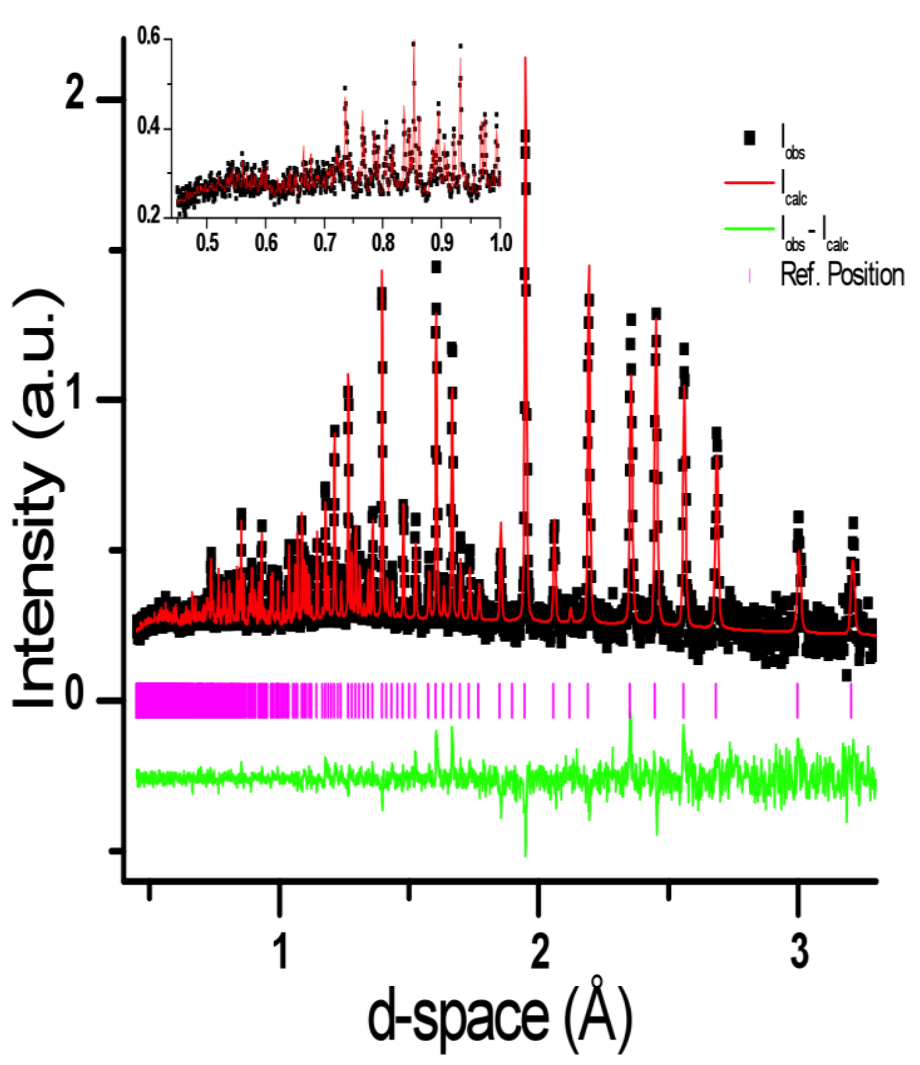

(a) 


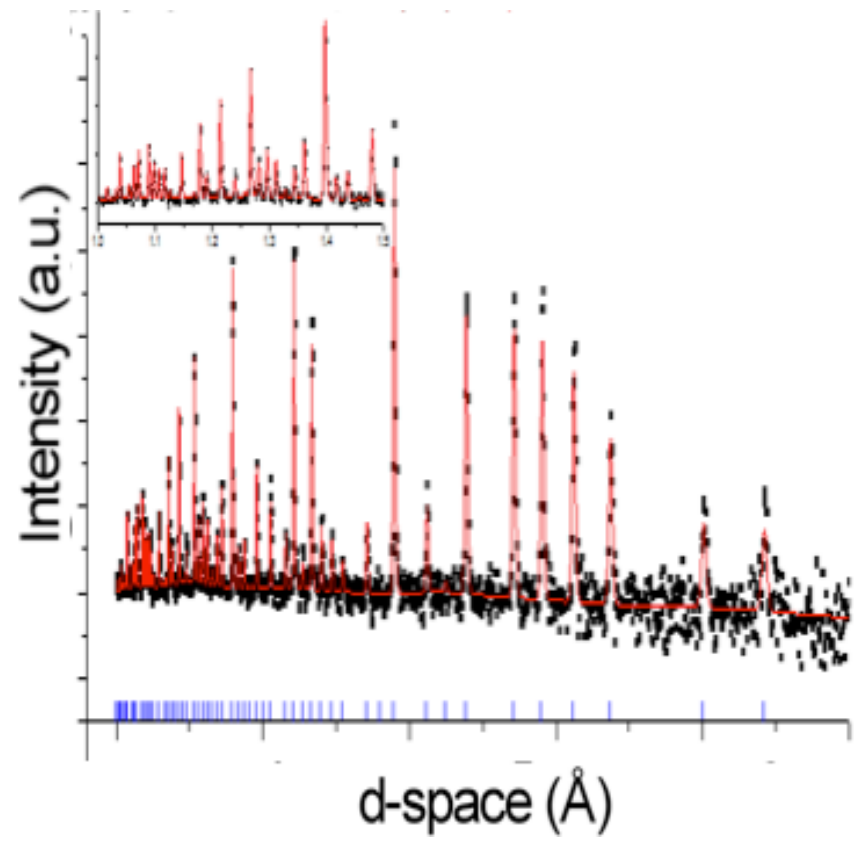

(b)

Figure 6: Refined neutron diffraction data collected at room temperature (298 K) for (a) undoped and (b) 0-3 Fe mayenite.

Samples were synthesized according to $\mathrm{Ca}_{12} \mathrm{Al}_{14}$ ${ }_{x} \mathrm{Fe}_{\mathrm{x}} \mathrm{O}_{33}$ indicating the $\mathrm{Fe}$ was substituting for the $\mathrm{Al}$ as suggested by Boysen [16]. To confirm this, neutron powder diffraction data were collected on a sample with $\mathrm{x}$ $=0.3$. The initial refinement used the model with one $\mathrm{Ca}$ position and the $\mathrm{O}$ in the $12 a$ position partially occupied and then a series of additional refinements were undertaken the $\mathrm{Fe}$ in all of the different framework cation sites. Without adding Fe to the structure and refining on 34 variables including all the atomic positions and atomic displacement parameters resulted in a $\chi^{2}=1.593(\mathrm{R} w p=$ $5.71 \%$ and Rexp $=4.55 \%$ ). Next the site occupancy factors of all atoms were refined and resulted in a slightly lower $\chi^{2}$ and statistically significant vacancies on sites with the exception of the $\mathrm{Al}$ on the $16 c$ site. Creating a model where the $\mathrm{Ca}$ and $\mathrm{Fe}$ shared a site while constraining the atomic positions and the atomic displacement parameters to be equal and refining on the site occupancies resulted in negative sof for $\mathrm{Fe}$ and a value greater than one for $\mathrm{Ca}$ and the refinement diverged. When Fe was placed on the Al sites separately the refinements did not diverge and slightly lower $\chi^{2}$ s were obtained $\left(\chi^{2}=1.587\right.$ when $\mathrm{Fe}$ replaced the $\mathrm{Al}$ on the $16 c$ position and $\chi^{2}=1.592$ when $\mathrm{Fe}$ replaced the $\mathrm{Al}$ on the $12 b$ site). Based on the refined compositions a more significant amount of $\mathrm{Fe}$ was located on the $16 c$ position. Two additional refinements were attempted one with $\mathrm{Fe}$ substituting on both $\mathrm{Al}$ sites and one with $\mathrm{Fe}$ substituting on all three cation sites. Both of these refinements resulting in slightly but not significantly lower $\chi^{2}$, especially given the fact that more variables were introduced using these models. Based on all these refinements it appears that $\mathrm{Fe}$ is substituting on to the $\mathrm{Al}$ $16 c$ site, however the calculated formula based on the refinement results was slightly low in $\mathrm{Al}$ and high in $\mathrm{Fe}$. For the samples with $\mathrm{x}=0$ and $\mathrm{x}=0.3$ the refined lattice constants were $a=11.9884(3)$ and 11.9934(3) $\AA$, respectively, agreeing with the lattice parameters refined using the x-ray powder diffraction data.

\subsection{Conductivity}

Resistance versus voltage for citrate gel synthesized mayenite samples with $\mathrm{x}=0,0.05,0.1$ and 0.3 is shown in Figure 7. The undoped sample showed a resistance of about $1.0 \times 10^{6} \Omega$, which was fairly constant at increased voltage. The contact resistance arising between the metal probe and the sample may have contributed to the somewhat high resistance observed in this sample. This is usually the case when using a 2-point probe. The Fe doped samples showed higher resistance increasing linearly with voltage. The higher resistance observed in the Fe doped samples could be a result of mobile electrons being trapped by the oppositely charged impurity centers created by Fe. The crystal structure of mayenite consists of a positively charged framework $\left[\mathrm{Ca}_{12} \mathrm{Al}_{14} \mathrm{O}_{32}\right]^{2+}$ and free oxygen $\mathrm{O}^{2-}$ distributed randomly within the cages of the framework to maintain the charge neutrality of the entire crystal. When the free oxygen ions are removed from the cages through reduction process, electrons are introduced to the cages to keep the charge neutrality of the crystal. These electrons bring about conductivity and conductivity changes from ionic to metallic as the electron concentration goes from low to high. But in a case where a dopant creates a dopant center or well that is deep, the electrons became electro-statically bound to these centers and become immobile.

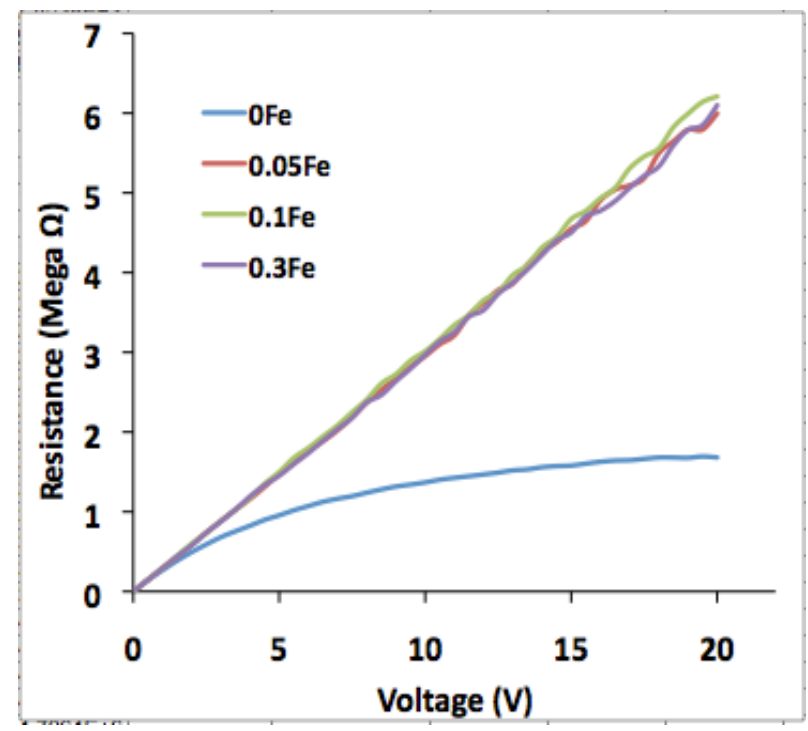

Figure 7: Graph of resistance versus voltage for citrate gel synthesized mayenite samples with $\mathrm{x}=0,0.05,0.1$ and 0.3 .

\subsection{CONCLUSIONS}

$\mathrm{Fe}$ was introduced into mayenite using both solidstate and citrate gel syntheses. Samples prepared using citrate gel were able to incorporate more $\mathrm{Fe}$ while 
maintaining phase purity compared to samples prepared using solid-state synthesis. It was observed that beyond 0.4 atomic $\%, \mathrm{Fe}$ started to precipitate out of samples using the citrate gel method. It was observed from the neutron data refinement that $\mathrm{Fe}$ occupies the $\mathrm{Al}$ positions instead of Ca position. The lattice parameter of mayenite was observed to increase with increased Fe content as a result of $\mathrm{Fe}$, with a larger ionic radius, compared to $\mathrm{Al}$. There was a decrease in conduction from the undoped to the doped mayenite, suggesting that $\mathrm{Fe}$ is not an appropriate dopant in enhancing the electrical properties of mayenite.

\section{ACKNOWLEDGEMENTS}

SNU was partly supported by Pipeline Engineering Diversity Program under DOE grant DEFG02-05ER25717, and partly sponsored by the Center for Materials Processing (CMP) at the University of Tennessee. The X-ray powder diffraction data were collected at the High Temperature Materials Laboratory at Oak Ridge National Laboratory (ORNL). The neutron powder diffraction data were collected at the Spallation Neutron Source at ORNL and sponsored by the Scientific User Facilities Division, Office of Basic Energy Sciences, U.S. Department of Energy. UT-Battelle LLC, for the US Department of Energy, manages ORNL. The authors will like to thank Carlos Gonzales for his help with the resistivity data collection and analysis.

\section{REFERENCES}

[1] Büssem, W. "Die Struktur des Pentacalciumtrialuminats." Zeitschrift für Kristallographie-Crystalline Materials 95(1-6), (1936), 175-188.

[2] Fujita, Satoru, et al. "Controlling the quantity of radical oxygen occluded in a new aluminum silicate with nanopores." Chemistry of materials, 15(26), (2003), 4879-4881.

[3] Li, Z., Yang, J., Hou, J.G. and Zhu, Q. "Is mayenite without clathrated oxygen an inorganic electride?". Angewandte Chemie International Edition, 43(47), (2004), 6479-6482.

[4] Sushko, P.V., Shluger, A.L., Hayashi, K., Hirano, M. and Hosono, H."Mechanisms of oxygen ion diffusion in a nanoporous complex oxide 12CaO.7 $\mathrm{Al}_{2} \mathrm{O}_{3}$." Physical Review B, 73(1), (2006), 014101.

[5] Hayashi, K., Ueda, N., Matsuishi, S., Hirano, M., Kamiya, T. and Hosono, H. "Solid state syntheses of $12 \mathrm{SrO} \cdot 7 \mathrm{Al}_{2} \mathrm{O}_{3}$ and formation of high density oxygen radical anions, $\mathrm{O}-$ and $\mathrm{O} 2-$-". Chemistry of Materials, 20(19), (2008), 5987-5996.

[6] Matsuishi, S., Toda, Y., Miyakawa, M., Hayashi, K., Kamiya, T., Hirano, M., Tanaka, I. and Hosono, $\mathrm{H}$. "High-density electron anions in a nanoporous single crystal:

[Ca24A128064] 4+(4e). Science, 301(5633), (2003), 626-629.

[7] Toda, Y., Matsuishi, S., Hayashi, K., Ueda, K., Kamiya, T., Hirano, M. and Hosono, H. "Field emission of electron anions clathrated in subnanometer-sized cages in [Ca24A128064] 4+(4e--)". Advanced materials, 16(8), (2004), 685689.

[8] Kamiya, T., Aiba, S., Miyakawa, M., Nomura, K., Matsuishi, S., Hayashi, K., Ueda, K., Hirano, M. and Hosono, H. "Field-Induced Current Modulation in Nanoporous Semiconductor Electron-Doped 12CaO९7Al2O3". Chemistry of materials, 17(25), (2005), 6311-6316.

[9] Trofymluk, O., Toda, Y., Hosono, H. and Navrotsky, A. "Energetics of formation and oxidation of microporous calcium aluminates: A new class of electrides and ionic conductors". Chemistry of materials, 17(22), (2005), 5574-5579.

[10] Fujita, S., Nakano, H., Suzuki, K., Mori, T. and Masuda, H. "Oxidative Destruction of Hydrocarbons on Ca12Al 14-x Si x O 33+ 0.5x $(0 \leq$ $\mathrm{x} \leq 4)$ with Radical Oxygen Occluded in Nanopores". Catalysis letters, 106(3), (2006), 139143.

[11] Li, C., Yamamoto, Y., Suzuki, M., Hirabayashi, D. and Suzuki, K. "Study on the combustion kinetic characteristics of biomass tar under catalysts". Journal of thermal analysis and calorimetry, 95(3), (2009) 991-997.

[12] Boysen, H., Kaiser-Bischoff, I. and Lerch, M. "Anion diffusion processes in $\mathrm{O}$-and $\mathrm{N}$-mayenite investigated by neutron powder diffraction". Diffusion Fundamentals, 8, (2008), 2.1-2.8.

[13] Dye, James L. "Electrides: from 1D Heisenberg chains to 2D pseudo-metals." Inorganic Chemistry, 36(18) (1997), 3816-3826.

[14] Domínguez, C., and Torrecillas, R. Influence of $\mathrm{Fe}<$ sup $>3+</$ sup $>$ on sintering and microstructural evolution of reaction sintered calcium hexaluminate, Journal of the European Ceramic Society, 18, (1998), 1373-1379.

[15] Boysen, H., Kaiser-Bischoff, I., Lerch, M., Berendts, S., Börger, A., Trots, D.M., Hoelzel, M. and Senyshyn, A. "Structures and properties of variously doped Mayenite investigated by neutron and synchrotron powder diffraction". Zeitschrift fur Kristallographie Supplements, 2009(30), 323-328.

[16] Ude, S., N., Claudia J. R., Roberta A. P., Melanie J. K., Gregory L. J., and Andrew P., E. "High temperature X-ray studies of mayenite synthesized using the citrate sol-gel method." Ceramics International, 40(1), (2014), 1117-1123.

[17] Larson, A. C., and Von Dreele, R. B. "Los Alamos National Laboratory Report LAUR, 1994 
(unpublished) Toby BH 2001, Journal of Applied Crystallography, 34 (2000) 210.

[18] Toby, B., H. "EXPGUI, a graphical user interface for GSAS." Journal of applied crystallography 34(2), (2001): 210-213.

[19] Huq, A., Hodges, J.P., Gourdon, O. and Heroux, L. "Powgen: A third-generation highresolution highthroughput powder diffraction instrument at the Spallation Neutron Source." Zeitschrift für Kristallographie Proceedings, 2011 (2011) 127135.

[20] Meunier, G. "Study on the structure of iron ores". II, Sintering in an Experimental Pot-Grate CRM Metallurgical Review, (1971), 5-16.

[21] Redhammer, G.J., Tippelt, G., Roth, G. and Amthauer, G. "Structural variations in the brownmillerite series $\mathrm{Ca} 2$ (Fe2- xAlx) O5: Singlecrystal X-ray diffraction at $25^{\circ} \mathrm{C}$ and hightemperature X-ray powder diffraction $\left(25^{\circ} \mathrm{C} \leq \mathrm{T} \leq\right.$ $1000^{\circ}$ C)". American Mineralogist, 89(2-3), (2004), 405-420.

[22] Bartl, H., Scheller, T. Zur Struktur des 12CaO-7Al2O3, Neues Jahrb. Mineral. Monatsh, 35, (1970), 547-552.

[23] Boysen, H., Lerch, M., Stys, A. and Senyshyn, A. Structure and oxygen mobility in mayenite $\left(\mathrm{Ca}_{12} \mathrm{Al}_{14} \mathrm{O}_{33}\right)$ : a high-temperature neutron powder diffraction study, Acta Crystallographica Section B: Structural Science, 63(5), (2007), 675-682 